\title{
Biomechanical Study of the Effects of Balloon Kyphoplasty on the Adjacent Vertebrae
}

\author{
Hiromitsu Takano, Ikuho Yonezawa ${ }^{1}$, Mitsugu Todo², Muhammad Hazli Mazlan ${ }^{3,4}$, \\ Tatsuya Sato', Kazuo Kaneko' ${ }^{1}$ \\ ${ }^{1}$ Division of Spine Surgery, Department of Orthopedic Surgery, School of Medicine, Juntendo University, Tokyo, Japan \\ ${ }^{2}$ Research Institute for Applied Mechanics, Kyushu University, Kasuga-City, Japan \\ ${ }^{3}$ Interdisciplinary Graduate School of Engineering Sciences, Kyushu University, Kasuga-City, Japan \\ ${ }^{4}$ Faculty of Electrical and Electronic Engineering, Universiti Tun Hussein Onn Malaysia, Parit Raja, Malaysia \\ Email: yoza@juntendo.ac.jp
}

How to cite this paper: Takano, H., Yonezawa, I., Todo, M., Mazlan, M.H., Sato, T. and Kaneko, K. (2016) Biomechanical Study of the Effects of Balloon Kyphoplasty on the Adjacent Vertebrae. J. Biomedical Science and Engineering, 9, 478-487.

http://dx.doi.org/10.4236/jbise.2016.910043

Received: July 12, 2016

Accepted: September 17, 2016

Published: September 20, 2016

Copyright $\odot 2016$ by authors and Scientific Research Publishing Inc. This work is licensed under the Creative Commons Attribution International License (CC BY 4.0).

http://creativecommons.org/licenses/by/4.0/ (c) (i) Open Access

\section{Abstract}

We used the finite element method (FEM) to investigate the stress profiles of vertebrae in patients who underwent balloon kyphoplasty (BKP) for vertebral fracture. $\mathrm{BKP}$ is often performed for persistent pain after vertebral fractures. However, fractures are frequently reported in the adjacent vertebrae after BKP. The purpose was to clarify the mechanism of fractures that occur in the adjacent vertebrae after BKP. The subjects were two patients (first case: 74-year-old woman; second case: 88 -yearold woman) who had BKP for osteoporotic vertebral fractures (L1). A bone analysis software program, Mechanical Finder, was used to construct three-dimensional finite element models (T11-L3) from computed tomographic (CT) digital imaging and communications in medicine (DICOM) data. Moment loadings were examined to evaluate stress concentrations on the vertebrae. Young's moduli were lower in the second case than in the first case at all vertebral levels. Maximum Drucker-Prager stresses after BKP were larger in the second case than in the first case for compression, flexion, extension, and axial rotation. Strain energy density decreased in L1 and increased in the adjacent vertebrae. Our results suggest that post-BKP fractures of the adjacent vertebrae not only are due to bone fragility, but also can be caused by increased rigidity in the vertebrae filled with bone cement, which increases stress concentration on the adjacent vertebrae and raises the likelihood of fracture.

\section{Keywords}

Biomechanics, Finite Element Method, Vertebral Compression Fracture, Balloon Kyphoplasty, Mechanical Analysis 


\section{Introduction}

As society ages, the number of osteoporosis patients has been increasing, turning bone fragility fractures into a major societal problem. Fractures can cause the loss of motor function, lead to other diseases, decrease quality of life, and cause elderly people to be bedridden-these are serious problems for aging societies. After osteoporosis is diagnosed, it is important to prevent fractures, or discover them early should they occur. Yet at present there is no established diagnostic method that allows the risk of fracture due to bone destruction to be evaluated quantitatively. Vertebral fractures are common in osteoporosis. While the basic treatment is conservative, balloon kyphoplasty (BKP) is often performed in cases with persistent pain. In this procedure, a balloon is inserted percutaneously into the fracture area to raise the vertebra, and then the area is filled with bone cement. However, fractures are said to occur frequently in the adjacent vertebrae after BKP. In the present study, we used the finite element method (FEM) to investigate the stress profiles of vertebrae in cases of vertebral fracture that had undergone BKP. Our purpose was to clarify the mechanism of fractures that occur in the adjacent vertebrae after BKP.

\section{Materials and Methods}

\subsection{Patient-Specific FE Modeling}

The patients provided written, informed consent prior to enrollment, and the study protocol was approved by the Ethics Committee of Juntendo University. The subjects were two patients (first case: 74-year-old woman, bone mineral density (BMD) T-score 69\%; second case: 88-year-old woman, BMD T-score 64\%) who underwent BKP for osteoporotic vertebral fractures (L1) at our hospital. They were consecutively recruited and studied from April 2015 to august 2015.Computed tomographic (CT) digital imaging and communications in medicine (DICOM) data was collected at 1-mm intervals after BKP was performed at L1 (Figure 1). The bone analysis software program Mechanical Finder (Research Center of Computational Mechanics Co., Japan) [1] was then
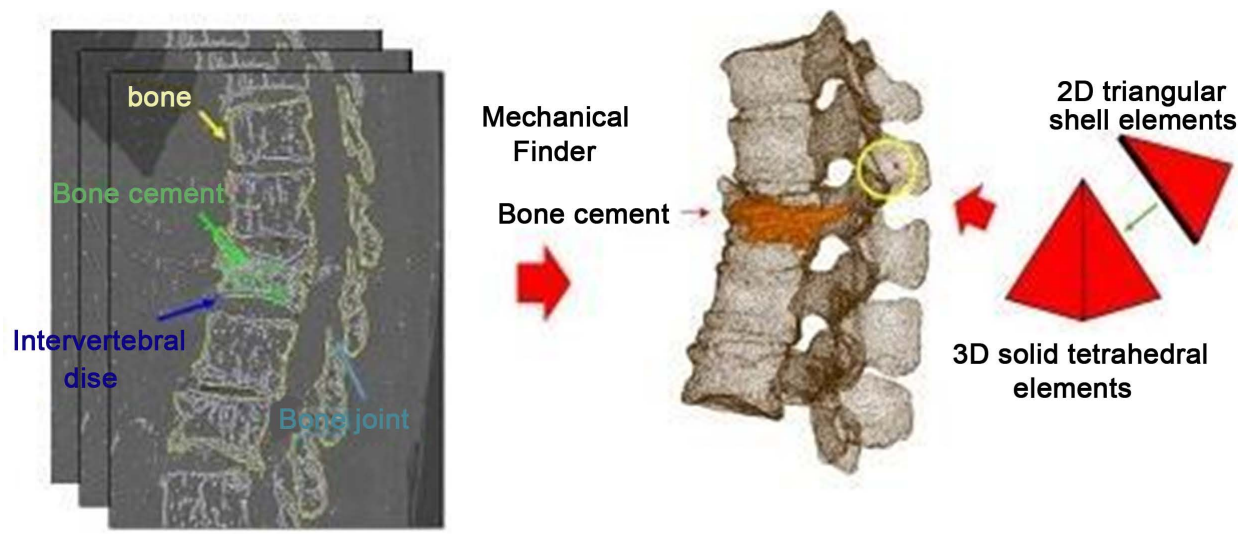

3D solid tetrahedral elements

Figure 1. Construction of 3D FE model. Bone geometrical features were extracted from CT DICOM by using Mechanical Finder (MF) software [9]. 
used to construct heterogeneous 3-dimensional (3D) finite element (FE) models (T11L3) (Figure 2). In each CT image, the regions of interest (ROI) were the outer edges of the cortical bone, which were used to create a numerical model of the anatomical structure of the vertebrae. This was also performed for the areas of bone cement HV-R in the postoperative models. The FE models were constructed from tetrahedral elements and shell elements. Tetrahedral elements with a mean size of $1 \mathrm{~mm}$ were used for the bone cement, inside of cortical bone, and cancellous bone. Shell elements $0.4 \mathrm{~mm}$ thick were used for the outside of cortical bone. On average, there were 1,500,454 and 1,566,517 tetrahedral solid elements and 191,620 and 211,230 triangular shell elements for first case model and second case model, respectively. To reflect the heterogeneity of actual bone structure, Young's modulus and compressive yield stresses were estimated from CT image Hounsfield unit (HU) values using Keyak et al.'s experimental formula [2]. Based on reports by Keyak et al. [2] and Reilly et al. [3], 0.4 was used for Poisson's ratio. Poisson's ratios for intervertebral discs and facet joint cartilage were 0.45 and 0.2 , respectively. Young's modulus for intervertebral discs and facet joint cartilage were 8.4 $\mathrm{MPa}$ and $11 \mathrm{MPa}$, respectively (Table 1). For bone cement, Young's modulus was 3.7 MPa and Poisson's ratio was 0.37 (Table 2) [4].

\subsection{Analysis}

The FE models were loaded with a compressive force of $1000 \mathrm{~N}$ in four rotational/ moment loadings on the superior surface of the T11 intervertebral disc. The models were made to simulate the four physiological motions of the spine: flexion, extension,

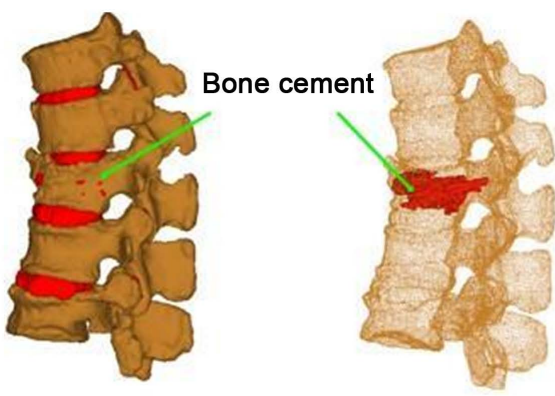

(a)

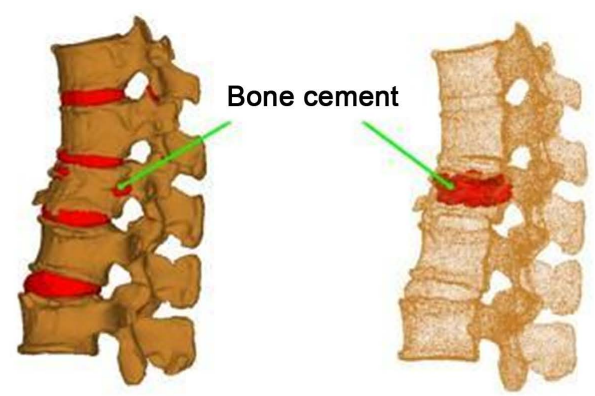

(b)

Figure 2. Finite element models: (a) First case; (b) Second case.

Table 1. Facet joint cartilages and intervertebral disc material properties.

\begin{tabular}{ccc}
\hline Material & Young's modulus & Poisson's ratio \\
\hline Intervertebral disc & $8.4 \mathrm{MPa}$ & 0.45 \\
Facet joint & $11 \mathrm{MPa}$ & 0.2 \\
\hline
\end{tabular}

Table 2. Bone cement material properties [4].

\begin{tabular}{ccccc}
\hline Material & Poisson's ratio & Young's modulus & Critical strength & Yield strength \\
\hline Bone cement & 3.7 & $3700 \mathrm{MPa}$ & $31 \mathrm{MPa}$ & $111 \mathrm{MPa}$ \\
\hline
\end{tabular}


lateral bending, and axial rotation. The inferior side of the L3 intervertebral disc was rigidly fixed. The loading details are listed and depicted in Table 3 and Figure 3, respectively [5]. We referenced the boundary conditions used by Zhang et al. [6], and loaded the vertebrae with $85 \%$ and the posterior components with $15 \%$ of the load. FEM analyses of the stress profiles after BKP were compared. Among the results, we focused on stress distributions on the vertebrae designations.

\section{Results}

Figure 4 shows the Young's modulus distributions. Young's modulus were lower in the second case than in the first case for all vertebrae. We measured the midsagittal and midlateral plane distance the halfway point of the midsagittal plane distance of the superior and inferior endplates. Maximum Drucker-Prager stresses after BKP in the first case and second case were, respectively, 22.7 MPa and 32.1 MPa for compression, 2.7 $\mathrm{MPa}$ and 6.4MPa for flexion, 0.4 $\mathrm{MPa}$ and 1.7 $\mathrm{MPa}$ for extension, 11.3 $\mathrm{MPa}$ and 5.9 $\mathrm{MPa}$ for lateral bending, and 9.2 $\mathrm{MPa}$ and 11.3 MPa for axial rotation (Figure 5). Figure 6 shows the strain energy distributions after BKP for compression, flexion, extension, lateral bending, and axial rotation loading. Strain energy density was concentrated on the superior and inferior vertebrae (T12, L2) under all the conditions. Average strain energy densities in the first case and second case were as follows. For compression the respective values for T12 were $31.65 \mathrm{KJ} / \mathrm{m}^{3}$ and $101.32 \mathrm{KJ} / \mathrm{m}^{3}$, for $\mathrm{L} 111.28 \mathrm{KJ} / \mathrm{m}^{3}$ and $13.98 \mathrm{KJ} / \mathrm{m}^{3}$, and for $\mathrm{L} 218.59 \mathrm{KJ} / \mathrm{m}^{3}$ and $37.07 \mathrm{KJ} / \mathrm{m}^{3}$. For flexion the respective values

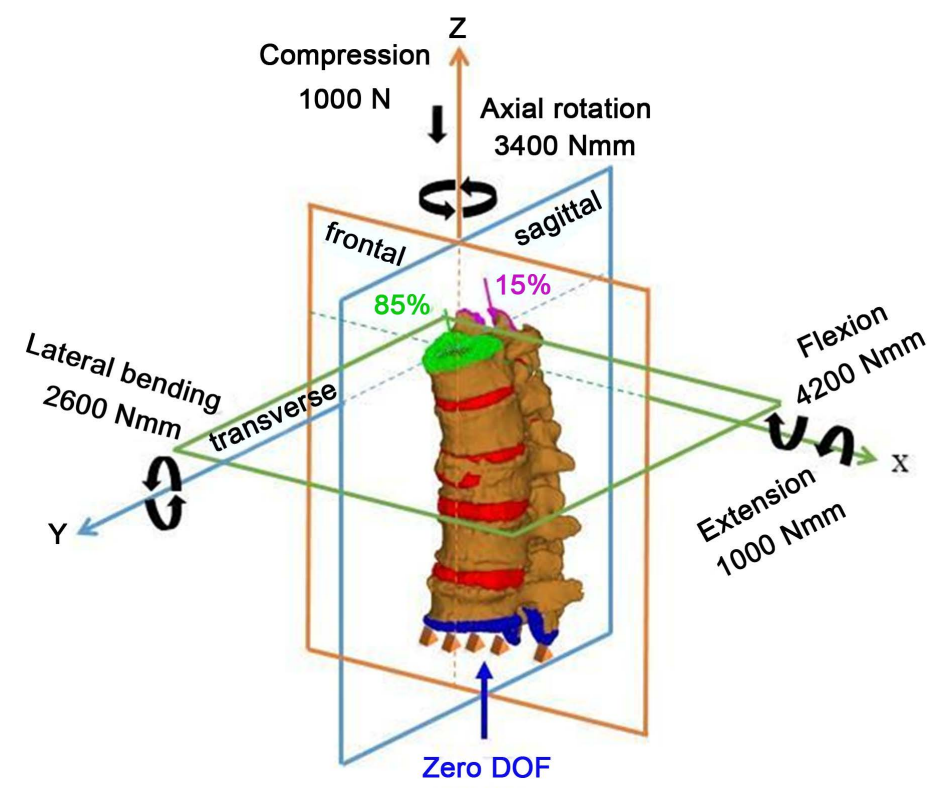

Figure 3. Loads and boundary conditions.

Table 3. Loading conditions [5].

\begin{tabular}{ccccc}
\hline Motion & Flexion & Extension & Lateral bending & Axial rotation \\
\hline Loading $(\mathrm{N} \cdot \mathrm{m})$ & 4.2 & 1.0 & 2.6 & 3.4 \\
\hline
\end{tabular}




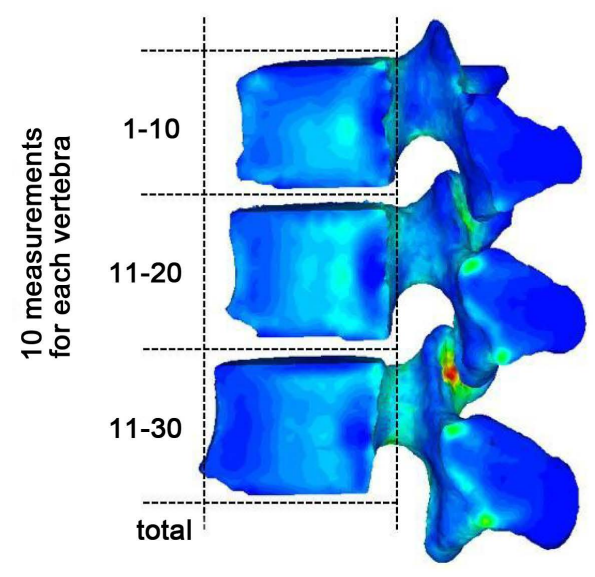

(a)

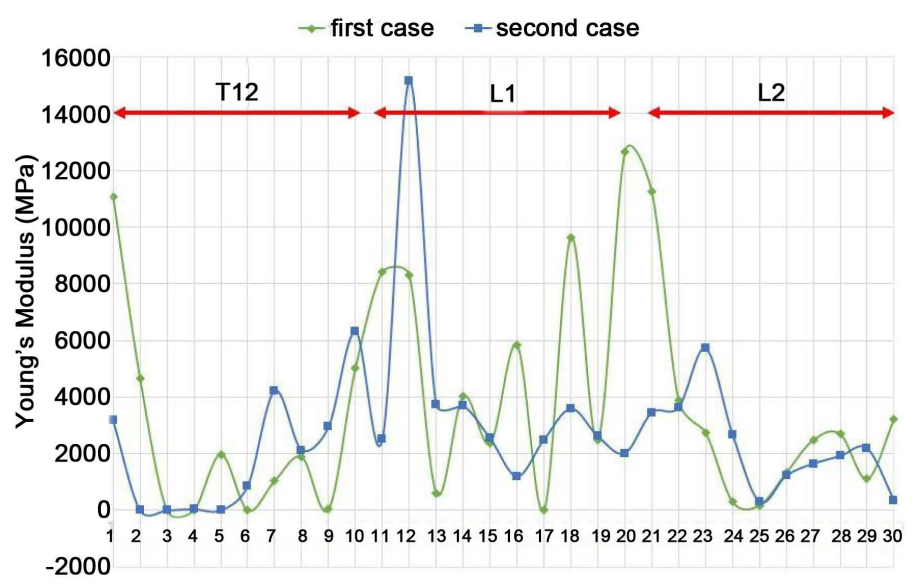

(b)

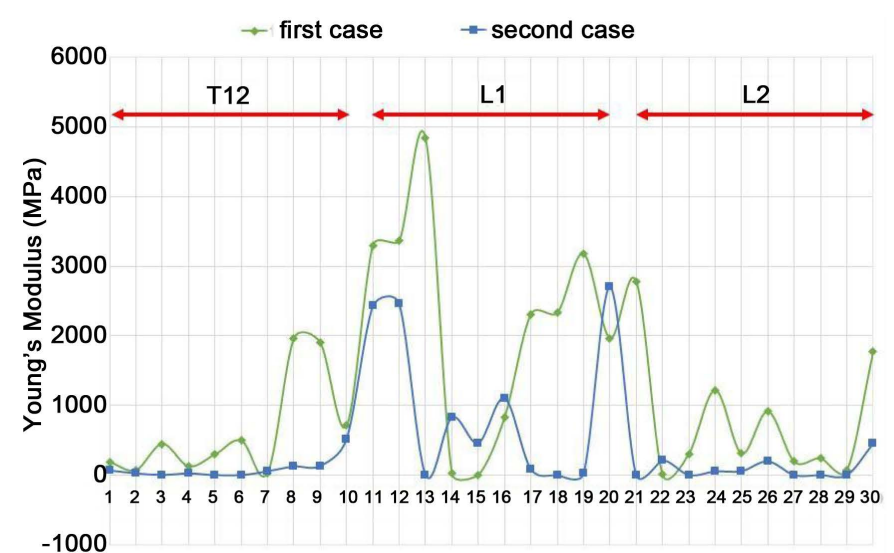

(c)

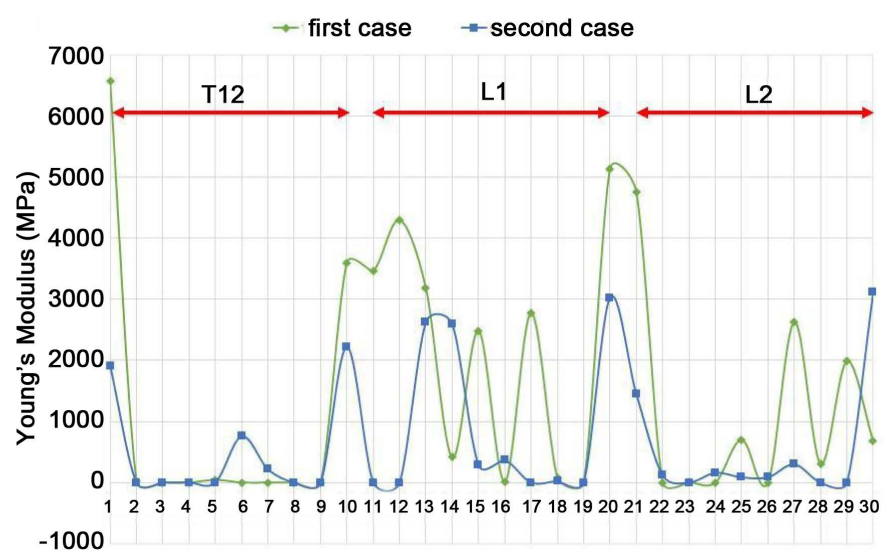

(d)

Figure 4. (a) Young's modulus distribution; (b) Anterior; (c) Central; (d) Posterior.

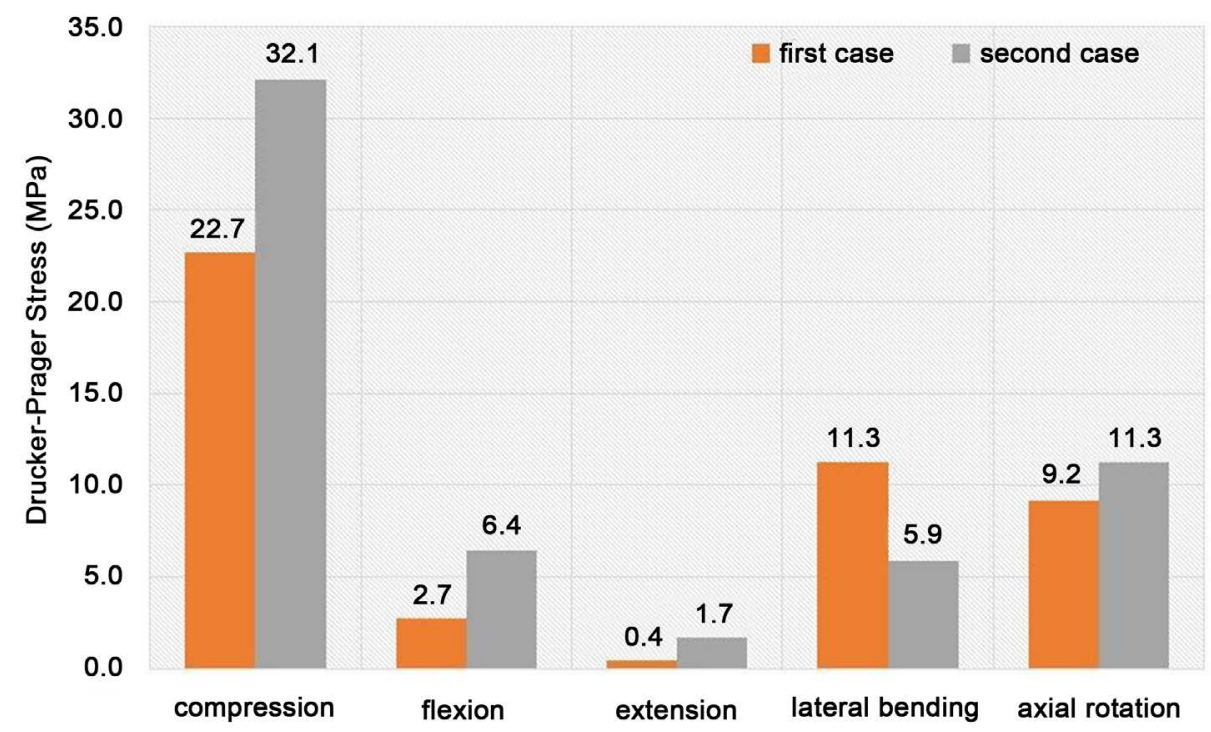

Figure 5. Maximum Drucker-Prager stress. Compression: first case 22.7 MPa, second case 32.1 MPa, flexion; first case 2.7 MPa, second case 6.4 MPa, extension; first case $0.4 \mathrm{MPa}$, second case $1.7 \mathrm{MPa}$, lateral bending; first case $11.3 \mathrm{MPa}$, second case $5.9 \mathrm{MPa}$, axial rotation; first case 9.2 $\mathrm{MPa}$, second case 11.3 $\mathrm{MPa}$. 


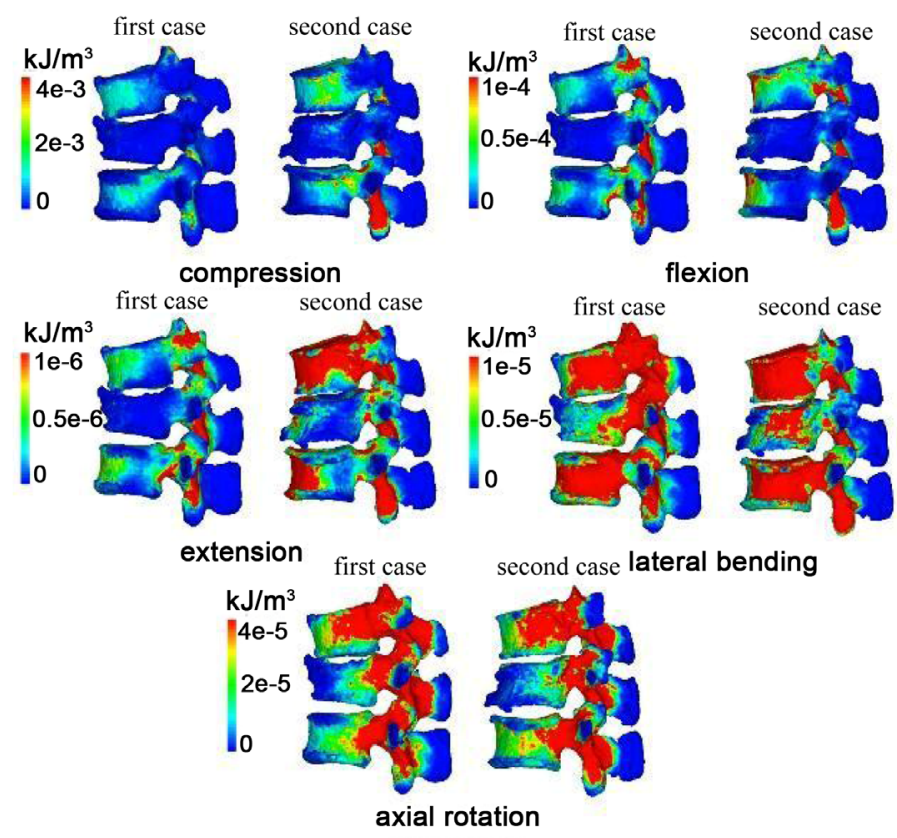

Figure 6. Strain energy density distribution.

for T12 were $0.90 \mathrm{KJ} / \mathrm{m}^{3}$ and $2.55 \mathrm{KJ} / \mathrm{m}^{3}$, for $\mathrm{L} 10.39 \mathrm{KJ} / \mathrm{m}^{3}$ and $1.15 \mathrm{KJ} / \mathrm{m}^{3}$, and for $\mathrm{L} 2$ $0.59 \mathrm{KJ} / \mathrm{m}^{3}$ and $1.85 \mathrm{KJ} / \mathrm{m}^{3}$. For extension the respective values for $\mathrm{T} 12$ were $0.01 \mathrm{KJ} / \mathrm{m}^{3}$ and $0.14 \mathrm{KJ} / \mathrm{m}^{3}$, for $\mathrm{L} 10.01 \mathrm{KJ} / \mathrm{m}^{3}$ and $0.07 \mathrm{KJ} / \mathrm{m}^{3}$, and for $\mathrm{L} 20.01 \mathrm{KJ} / \mathrm{m}^{3}$ and 0.10 $\mathrm{KJ} / \mathrm{m}^{3}$. For lateral bending the respective values for $\mathrm{T} 12$ were $0.78 \mathrm{KJ} / \mathrm{m}^{3}$ and 1.84 $\mathrm{KJ} / \mathrm{m}^{3}$, for $\mathrm{L} 10.80 \mathrm{KJ} / \mathrm{m}^{3}$ and $0.84 \mathrm{KJ} / \mathrm{m}^{3}$, and for $\mathrm{L} 20.35 \mathrm{KJ} / \mathrm{m}^{3}$ and $1.11 \mathrm{KJ} / \mathrm{m}^{3}$. For axial rotation the respective values for T12 were $1.78 \mathrm{KJ} / \mathrm{m}^{3}$ and $0.78 \mathrm{KJ} / \mathrm{m}^{3}$, for $\mathrm{L} 10.49$ $\mathrm{KJ} / \mathrm{m}^{3}$ and $0.80 \mathrm{KJ} / \mathrm{m}^{3}$, and for $\mathrm{L} 21.50 \mathrm{KJ} / \mathrm{m}^{3}$ and $0.35 \mathrm{KJ} / \mathrm{m}^{3}$ (Figure 7). Note, the strain energy density of L1 was reduced and the strain energy densities of the adjacent vertebrae were increased.

\section{Discussion}

Recent advancements in computational mechanics technology have enabled mechanical analyses using FEM that reflect the complex structural morphology and material characteristics of bone [7]. These techniques are being applied to FEM analyses of vertebral fractures. For example, 3D bone models have been constructed from DICOM data obtained from quantitative CT images. FEM has then been used to perform stress analyses to quantify strengths under external force from different directions and of different sizes [8]-[10]. Recent attempts that take individual patients' bone strengths into consideration have used CT data to understand the pathology of and assess therapeutic effects in osteoporosis [11] [12]. These techniques have also been used to evaluate surgeries using instrumentation [13]. One important issue for bone FEM has been how to treat the distribution of bone density in the modeling stage. Keyake et al. proposed an experimental formula that uses concentration distributions from $\mathrm{CT}$ images to reflect bone density [14]. They verified the accuracy of this formula. This formula also strongly 


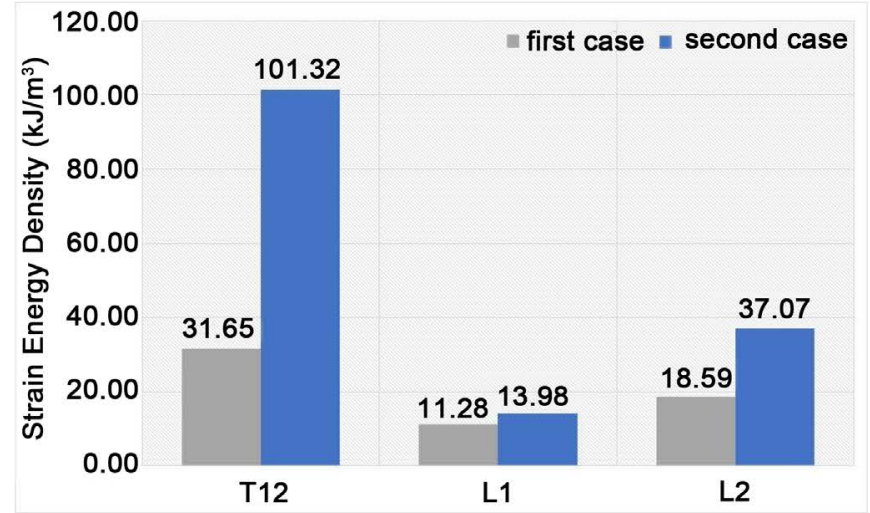

(a)

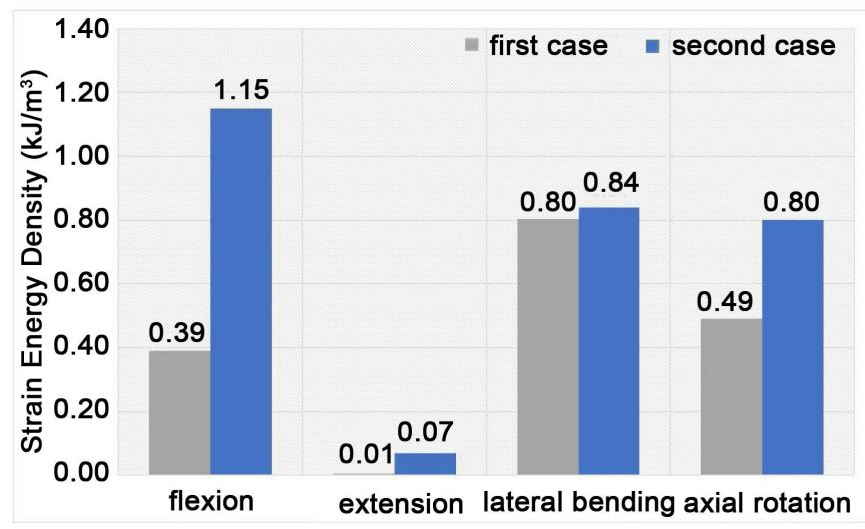

(c)

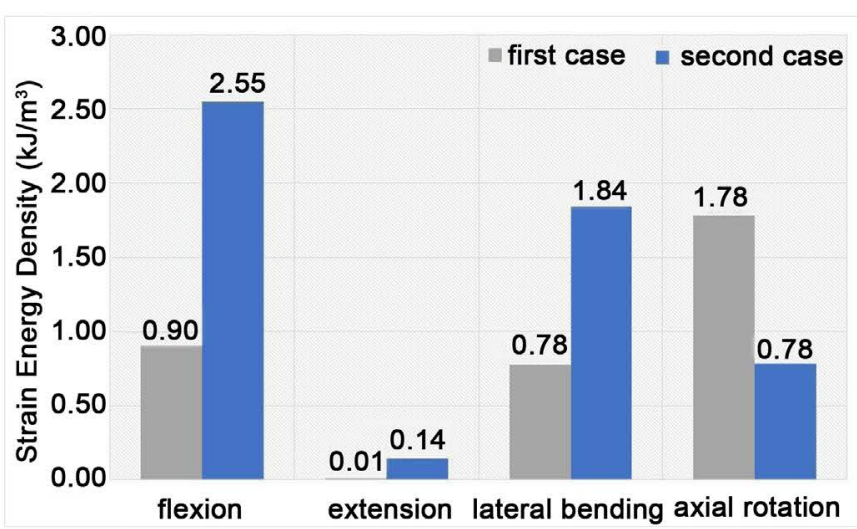

(b)

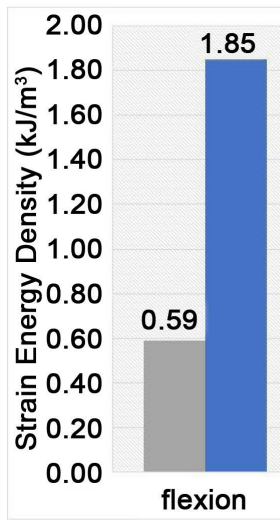

flexion w first case $=$ second case

1.50

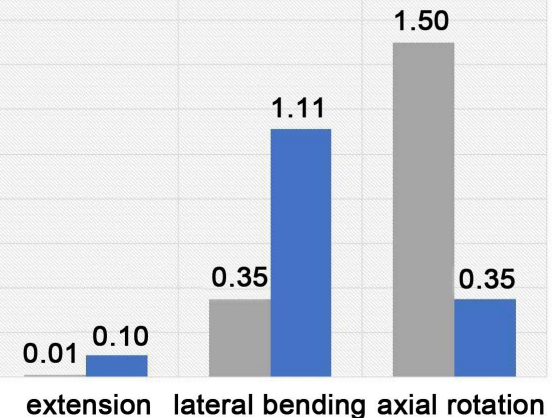

(d)

Figure 7. Average strain energy density: (a) Compression; (b) T12; (c) L1; (d) L2 Compression; T12 first case $31.65 \mathrm{KJ} / \mathrm{m}^{3}$, second case $101.32 \mathrm{KJ} / \mathrm{m}^{3}$, L1 first case $11.28 \mathrm{KJ} / \mathrm{m}^{3}$, second case $13.98 \mathrm{KJ} / \mathrm{m}^{3}$, L2 first case $18.59 \mathrm{KJ} / \mathrm{m}^{3}$, second case $37.07 \mathrm{KJ} / \mathrm{m}^{3}$.

correlates with the results of vertical compression load tests on lumbar vertebral samples from fresh cadavers and FEM by using CT data [15].

BKP is a superior surgical method that can quickly alleviate persistent pain due to vertebral fractures and can be safely performed in elderly people due to its low level of invasiveness. However, there have been numerous reports of intraoperative and postoperative complications with BKP. Fractures of the adjacent vertebrae after BKP are a particularly significant problem. Reported incidence rates of the adjacent vertebral fractures vary from $9.0 \%$ to $50 \%$ [16]. Lindsay et al. reported that the incidence rate of new secondary vertebral fractures was $19.2 \%$ from natural causes [17]. This indicates that BKP could be a contributing factor in increasing the incidence of vertebral fractures, especially considering that these fractures often occur within a few months of surgery.

In the present study, the CT data were from a 74-year-old woman and an 88-year-old woman, respectively. Bone density and Young's modulus were lower in the second patient. In addition, maximum Drucker-Prager stresses were higher in the second case than in the first for compression, flexion, extension, lateral bending, and axial rotation. These findings indicate that the second patient was at higher risk of a secondary verte- 
bral fracture. Elevated stress concentration in a vertebra increases the likelihood of damage to that vertebra, particularly in elderly people with reduced bone concentration [11].

The strain energy density distributions after BKP showed increased concentrations in the adjacent vertebrae (T12, L2) for all conditions, which indicates that stress concentration increased in the vertebrae centered around the vertebra that was filled with bone cement. Bone cement increased rigidity in the filled vertebra, while elevating stress concentration in the adjacent vertebrae [6] [18].

In both cases, the average strain energy density in L1 was markedly reduced. We believe this was caused by BKP increasing the rigidity of $\mathrm{L} 1$ and constraining the deformation [19]. Reduced bone density of L1 due to stress shielding is also suggested. We believe that reduced strain energy density at L1 caused strain energy density to rise in the adjacent vertebrae, and thus elevated structural instability. Clinically, the vast majority of the adjacent vertebral fractures after BKP occur in the vertebrae immediately above and below, which is consistent with our results. The results of the present study indicate that $\mathrm{BKP}$ is more of a contributing factor in the adjacent vertebral fractures than are natural causes. However, BKP is a beneficial therapy that can quickly relieve pain and improve the activities of daily living. Actually, this study patients relieved pain after BKP. Further investigation into spinal alignment, vertebral height, optimal amount of bone cement, and other factors are needed to help prevent fractures in the adjacent vertebrae. The limitations of this study are a small sample size and we don't have experimental validations. Validation study is very difficult, but we hope to try cadaver study.

\section{Conclusion}

We used the finite element method to quantitatively evaluate changes in stress concentration in vertebrae after balloon kyphoplasty. Our results suggest that adjacent vertebral fractures after balloon kyphoplasty are due not only to bone fragility, but also increased rigidity in the vertebrae filled with bone cement, which raises the stress concentration on the adjacent vertebrae and increases the likelihood of fracture.

\section{Acknowledgements}

Written informed consent was obtained from the patient for publication of this paper and for the use of any ac-companying images.

\section{Conflict of Interest}

The authors report no conflict of interest concerning the findings specified in this paper.

\section{References}

[1] Tawara, D., Sakamoto, J., Murakami, H., Kawahara, N., Oda, J. and Tomita, K. (2010) Mechanical Evaluation by Patient-Specific Finite Element Analysis Demonstrates Therapeutic Effects for Osteoporotic Vertebrae. Journal of the Mechanical Behavior of Biomedical Ma- 
terials, 3, 31-40. http://dx.doi.org/10.1016/j.jmbbm.2009.03.001

[2] Keyak, J.H., Rossia, S.A., Jones, K.A. and Skinner, H.B. (1998) Prediction of Femoral Fracture Load Using Automated Finite Element Modeling. Journal of Biomechanics, 31, 125 133. http://dx.doi.org/10.1016/S0021-9290(97)00123-1

[3] Reilly, D.T. and Burstein, A.H. (1975) The Elastic and Ultimate Properties of Compact Bone Tissue. Journal of Biomechanics, 8, 393-405. http://dx.doi.org/10.1016/0021-9290(75)90075-5

[4] Kurtz, S.M., Villarragaa, M.L., Zhao, K. and Edidin, A.A. (2005) Static and Fatigue Mechanical Behavior of Bone Cement with Elevated Barium Sulfate Content for Treatment of Vertebral Compression Fractures. Biomaterials, 17, 3699-3712.

http://dx.doi.org/10.1016/j.biomaterials.2004.09.055

[5] Han, K.S., Rohlmann, A., Zander, T. and Taylor, W.R. (2013) Lumbar Spinal Loads Vary with Body Height and Weight. Medical Engineering and Physics, 35, 969-977.

http://dx.doi.org/10.1016/j.medengphy.2012.09.009

[6] Zhang, L., Yang, G., Wu, L. and Yu, B. (2010) The Biomechanical Effects of Osteoporosis Vertebral Augmentation with Cancellous Bone Granules or Bone Cement on Treated and Non-Treated Vertebral Bodies: A Finite Element Evaluation. Clinical Biomechanics, 25, 166-172. http://dx.doi.org/10.1016/j.clinbiomech.2009.10.006

[7] Brekelmans, W.A., Poort, H.W. and Slooff, T.J. (1972) A New Method to Analyze the Mechanical Behavior of Skeletal Parts. Acta Orthopaedica Scandinavica, 43, 301-317. http://dx.doi.org/10.3109/17453677208998949

[8] Bauer, J.S., Sidorenko, I., Mueller, D., Baum, T., Issever, A.S., Eckstein, F., Rummeny, E.J., Link, T.M. and Reath, C.W. (2014) Prediction of Bone Strength by CT and MDCT-Based Finite-Element-Models: How Much Spatial Resolution Is Needed. European Journal of Radiology, 83, e36-e42. http://dx.doi.org/10.1016/j.ejrad.2013.10.024

[9] Julienne, E.B., Floor, M.L., Van Rietbergen, B., Ito, K. and Huiskes, R. (2009) Comparison of Bone Loss Induced by Ovariectomy and Neurectomy in Rats Analyzed by In Vivo MicroCT. Journal of Orthopaedic Research, 27, 1521-1527. http://dx.doi.org/10.1002/jor.20913

[10] Mazlan, M.H., Todo, M., Takano, H. and Yonezawa, I. (2014) Finite Element Analysis of Osteoporotic Vertebrae with First Lumbar (L1) Vertebral Compression Fracture. International Journal of Applied Physics and Mathematics, 4, 267-274. http://dx.doi.org/10.7763/IJAPM.2014.V4.297

[11] Lavelle, W.F. and Cheney, R. (2006) Recurrent Fracture after Vertebral Kyphoplasty. Spine Journal, 6, 488-493. http://dx.doi.org/10.1016/j.spinee.2005.10.013

[12] Tawara, D., Sakamoto, J., Murakami, H., Kawahara, N. and Tomita, K. (2011) Patient Specific Finite Element Analyses Detect Significant Mechanical Therapeutic Effects on Osteoporotic Vertebrae during a Three-Year Treatment. Journal of Biomechanical Science and Engineering, 6, 248-261. http://dx.doi.org/10.1299/jbse.6.248

[13] Mazlan, M.H., Todo, M., Takano, H. and Yonezawa, I. (2015) Effect of Cage Insertion Orientation on Stress Profiles and Subsidence Phenomenon in Posterior Lumbar Interbody Fusion. Journal of Medical and Bioengineering, 5, 93-97.

[14] Keyak, J.H. (2001) Improved Prediction of Proximal Femoral Fracture Load Using Nonlinear Finite Element Models. Medical Engineering and Physics, 23, 165-173. http://dx.doi.org/10.1016/S1350-4533(01)00045-5

[15] Silva, M.J., Wang, C., Keaveny, T.M. and Hayes, W.C. (1994) Direct and Computed Tomography Thickness Measurements of the Human, Lumbar Vertebral Shell and Endplate. Bone, 15, 409-414. http://dx.doi.org/10.1016/8756-3282(94)90817-6 
[16] Taylor, R.S., Fritzell, P. and Taylor, R.J. (2012) Balloon Kyphoplasty in the Management of Vertebral Compression Fractures: An Updated Systematic Review and Meta-Analysis. European Spine Journal, 16, 1085-1100. http://dx.doi.org/10.1007/s00586-007-0308-z

[17] Lindsay, R., Silverman, S.L. and Cooper, C. (2001) Risk of New Vertebral Fracture in the Year Following a Fracture. The Journal of the American Medical Association, 285, 320-323. http://dx.doi.org/10.1001/jama.285.3.320

[18] Luo, J., Adams, M.A. and Dolan, P. (2010) Vertebroplasty and Kyphoplasty Can Restore Normal Spine Mechanics Following Osteoporotic Vertebral Fracture. Journal of Osteoporosis, [Epub]. http://dx.doi.org/10.4061/2010/729257

[19] Chiang, C.K. and Wang, J.L. (2006) Strain Energy Density Variations of Osteoporotic Spine Column after Bone Cement Augmentation-An In Vitro Porcine Biomechanical Model. Journal of Biomechanics, 39, S150. http://dx.doi.org/10.1016/S0021-9290(06)83504-9

\section{Submit or recommend next manuscript to SCIRP and we will provide best service for you:}

Accepting pre-submission inquiries through Email, Facebook, LinkedIn, Twitter, etc. A wide selection of journals (inclusive of 9 subjects, more than 200 journals)

Providing 24-hour high-quality service

User-friendly online submission system

Fair and swift peer-review system

Efficient typesetting and proofreading procedure

Display of the result of downloads and visits, as well as the number of cited articles

Maximum dissemination of your research work

Submit your manuscript at: http://papersubmission.scirp.org/

Or contact jbise@scirp.org 